\title{
Desempenho de plântulas de canola sob variação da profundidade de semeadura e diferentes substratos
}

\author{
Performance of canola seedlings under sowing depth variation and different substrates \\ I. P. Santos ${ }^{1}$; A. R. Costa ${ }^{1 *}$; P. C. Silva ${ }^{1}$; A. A. L. Drumond ${ }^{2}$; F. F. Silva ${ }^{1}$ \\ ${ }^{1}$ Universidade Estadual de Goiás, Unidade Universitária Santa Helena de Goiás, 75920-000, Santa Helena de \\ Goiás-GO, Brasil \\ ${ }_{2}^{2}$ Instituto Federal Goiano, Campus Rio Verde, 75901-970, Rio Verde-GO, Brasil \\ *adriana.costa@ueg.br
}

(Recebido em 17 de fevereiro de 2020; aceito em 24 de maio de 2020)

\begin{abstract}
A canola é uma cultura que tem crescido no Brasil, e trata-se de uma fonte produtora de óleo. É uma cultura adaptada a climas frios e o conhecimento sobre o desenvolvimento inicial da canola pode contribuir para um melhor entendimento e estabelecimento destes híbridos em outras regiões. Objetivou-se avaliar o desempenho de plântulas de canola sob variação da profundidade de semeadura e diferentes substratos. Desta forma, foi conduzido um experimento em campo, em ambiente protegido, usando um esquema de parcelas subdivididas $2 \times 2 \times 3$, dois substratos (areia e solo), com dois híbridos de canola (Hyola 61 e Hyola 433), em três profundidades de semeadura $(1,2$ e $3 \mathrm{~cm}$ ), com oito repetições, resultando em 96 unidades experimentais. Em cada unidade experimental semearam-se 25 sementes que foram avaliadas por meio da contagem diária da emergência, até o ponto de sua estabilização, que ocorreu no décimo dia. Assim, se iniciaram as avaliações definidas de Comprimento de raiz (CR), Comprimento de plântula inteira (CPI), Altura de plântula (ALT), Plântulas normais (PN), Plântulas anormais (PA), Emergência de plântulas (E), Índice de velocidade de emergência (IVE), Massa fresca de plântulas (MFP) e Massa seca de plântulas (MSP). Observou-se que os híbridos tiveram melhor desempenho em substrato solo, com superioridade do hibrido Hyola 433 na semeadura a $1 \mathrm{~cm}$ de profundidade.
\end{abstract}

Palavras-chave: Brassica napus L., Hyola 61, Hyola 433.

Canola is a crop that has been incresing considerably in Brazil, as an important oil producer. It is crop adapted to cold climates and knowledge about the early growth of canola can contribute to a better understanding and establishment of this crop in other regions. The objective of this work was to evaluate the performance of canola seedlings under varying sowing depth and different substrates. Thus, an experiment was carried out in the field, in a protected environment, using a $2 \times 2 \times 3$ subdivided plot scheme, two substrates (sand and soil), two canola hybrids (Hyola 61 and Hyola 433), and three sowing depths (1, 2 and $3 \mathrm{~cm}$ ). Ninety-six plots, with 25 seeds each, were evaluated daily by counting of planting emergence, until the point of stabilization, which occurred on the tenth day. Thus, has began the characteristics evaluations of Root length (CR), Whole seedling length (CPI), Seedling height (Alt), Normal seedlings $(\mathrm{PN})$, Abnormal seedlings (PA), Seedling emergence (E), Emergency speed index (IVE), Fresh seedling mass (MFP) and Dry seedling mass (MSP). It was observed that the hybrids performed better in soil, with superiority of the Hyola 433 hybrid when sowing at $1 \mathrm{~cm}$ depth.

Keywords: Brassica napus L., Hyola 61, Hyola 433.

\section{INTRODUÇÃO}

A canola (Brassica napus L. var. oleifera) é uma opção de cultura para os sistemas de rotação bem como sucessão de culturas, principalmente no Sul do Brasil, assim como opção de renda extra para o produtor rural no inverno $[1,2]$. No Brasil, na safra 2019, a área plantada foi de 34 mil hectares, produzindo 46 mil toneladas de grãos, com produtividade média de $1.353 \mathrm{~kg} \mathrm{ha}^{-1}$ [3]. Entre os principais usos do grão, tem-se a extração de óleo para consumo humano, fabricação de sabão e, produção de biocombustível, gerando assim um sub-produto, o farelo, que pode ser utilizado na formulação de rações para animais $[4,5,6]$.

$\mathrm{O}$ crescimento na demanda brasileira pela exploração da canola e a busca por técnicas e manejos que desenvolvam a produção tem impulsionado pesquisas com a cultura [7]. No entanto, informações técnico-científicas no Brasil quanto ao manejo inicial do cultivo da canola são incipientes [8]. Entre elas, o desenvolvimento inicial de plântulas de novos híbridos, são fatores 
pouco estudados e podem trazer uma perspectiva de desempenho de híbridos, correlacionado a fatores extrínsecos à semente, como por exemplo, a profundidade de semeadura e o tipo de substratos no cultivo.

Um dos principais híbridos que tem sido cultivado nas lavouras do Brasil é Hyola 61 de origem australiana [9] que possui ciclo médio, o qual varia de 123 a 155 dias da emergência até a maturação e possui alta estabilidade de produtividade quando cultivado em diferentes condições e bom desempenho no que se refere à deficiência hídrica e baixa temperatura [10]. Outro híbrido que tem se destacado é o Hyola 433 o qual possui ciclo mais curto, indicado para os solos de elevada fertilidade, porém sensíveis a déficits hídricos [10].

Um fator importante no manejo da canola é a semeadura, que em profundidade ideal, confere rapidez e uniformidade de emergência das plântulas, e contribui para que as sementes expressem seu potencial de germinação, favorecendo o estabelecimento e crescimento da cultura [11, 12].

No entanto, o processo de semeadura da canola é uma etapa que enfrenta dificuldades, pois as sementes apresentam 2,0 mm de diâmetro e massa de mil grãos em torno de 3,0 a 6,0 g, o que dificulta a distribuição uniforme no solo, em relação à quantidade e a profundidade de deposição [13]. A profundidade de semeadura pode afetar o período de suscetibilidade a patógenos, e caso seja superficial, as sementes ficarão expostas a situações que podem gerar um estresse, bem como, prejudicar diretamente o desenvolvimento da plântula.

A canola não possui uma maturação uniforme [144], o que pode ocasionar um déficit na qualidade das sementes durante as etapas de processamento. A qualidade fisiológica da semente é averiguada conforme teste de germinação o qual é efetuado sob condições ideais de ambiente e, expressa e o máximo potencial de germinação, estabelece também o limite quanto ao desempenho do lote pós semeadura [155]. No entanto, devido suas limitações, podem ser observadas frequentes discrepâncias na emergência de plântulas em campo [16], em função de fatores como profundidade de semeadura [17] e tipo de solo, sendo, por isso, importante a avaliação de estabelecimento de plântulas em diferentes condições. Além disso, é importante obter informações que possam identificar híbridos que tenham melhor desempenho de estabelecimento de plântulas a fim de se alcançar maior produtividade de grãos.

Logo, o objetivo dessa pesquisa foi avaliar o desempenho de plântulas de híbridos de canola em diferentes profundidades de semeadura e substratos.

\section{MATERIAL E MÉTODOS}

O estudo foi realizado na Universidade Estadual de Goiás, Unidade Universitária Santa Helena de Goiás (1748'49”'S; 50³5’49”'W, 595 m de altitude), no Sudoeste de Goiano. De acordo com Alvares et al. (2013) [18], a região tem clima clasificado como Aw. A precipitação anual tem distribuição bimodal e atinge aproximadamente $1500 \mathrm{~mm}$ anuais, com duas estações definidas: estação seca ou inverno (maio a outubro) e chuvosa ou verão (novembro a abril) e temperatura média $25^{\circ} \mathrm{C}$.

Os tratamentos experimentais foram definidos por dois híbridos (Hyola 61 e Hyola 433); dois substratos (areia média e Latossolo Vermelho Distrófico, de textura argilosa, típico da região em estudo) e três profundidades de semeadura $(1,2 \mathrm{e} 3 \mathrm{~cm})$. Ao todo foram 48 parcelas experimentais para cada leito, totalizando 96 parcelas. O delineamento experimental empregado foi $\mathrm{o}$ inteiramente casualizado em esquema de parcelas subdivididas em $2 \times 2 \times 3$ (substrato; híbrido e profundidade de semeadura, respectivamente), com oito repetições, totalizando 96 unidades experimentais, constituídas por 25 sementes cada.

Realizou-se a semeadura em canteiros (de $1 \mathrm{~m}$ de largura por $8 \mathrm{~m}$ de comprimento e $0,4 \mathrm{~m}$ de profundidade) em ambiente protegido no dia 11 de setembro de 2017, utilizando-se 25 sementes por unidade experimental (linha de semeadura no canteiro) conforme especificações da Regra de Análise de Sementes (RAS) [15]. Para avaliar os efeitos de diferentes profundidades de semeadura e substratos sobre o desempenho de plântulas de canola realizaram-se as seguintes análises:

Emergência de plântulas: contagem do número de plântulas emergidas a partir do primeiro dia após a emergência, diariamente em um horário definido até estabilização da emergência, conforme RAS [15]. Os dados foram escritos em porcentagem de plântulas emergidas. 
Considerou-se como plântula normal a que mostrou potencial para se desenvolver dando origem a plantas normais, quando cultivadas em condições favoráveis [15]. Esta apresentou raiz principal ereta com raízes secundárias curtas e finas, caule levemente tortuoso, como a região entre a raiz e o caule não é bem delimitada então foi considerado caule a partir do primeiro aparecimento de raiz, sendo considerada plântula anormal aquela que não apresentou potencial para continuar seu desenvolvimento e dar origem a plantas normais em condições adequadas [15].

Índice de velocidade de emergência: $O$ índice de velocidade de emergência foi conduzido juntamente ao teste de emergência de plântulas, com anotações diárias, em mesmo horário, o índice de velocidade de emergência proposto por Maguire (1962) [19], representado pela equação 1. Foi avaliada a porcentagem final de emergência, em que se consideraram apenas as plântulas normais.

Em que:

$$
\mathrm{IVE}=\frac{\mathrm{G} 1}{\mathrm{~N} 1}+\frac{\mathrm{G} 2}{\mathrm{~N} 2}+\cdots+\frac{\mathrm{GN}}{\mathrm{Nn}} \quad(\text { Equação 1) }
$$

IVE = índice de velocidade de emergência;

$\mathrm{G} 1, \mathrm{G} 2, \ldots, \mathrm{Gn}=$ número de plântulas normais anotadas na primeira contagem, na segunda contagem e na última contagem;

$\mathrm{N} 1, \mathrm{~N} 2, \ldots, \mathrm{Nn}=$ Número de dias desde a semeadura na primeira contagem, na segunda contagem e à última contagem.

Após 10 dias da semeadura, efetuaram-se avaliações do desempenho das plântulas, com amostragem de 12 plântulas por unidade experimental. Para isso mensurou-se o Comprimento de Plântulas (CP), do ápice radicular até o ápice apical, medida $\mathrm{em} \mathrm{cm}$ com auxílio de régua graduada; Comprimento da Parte Aérea (CPA) mensurou-se desde o colo da plântula até o meristema apical, com auxílio da régua graduada em milímetros cujos resultados expressos em cm plântula ${ }^{-1}$; Comprimento da Raiz (CR) aferiu-se desde o colo até a extremidade da raiz principal, medida em $\mathrm{cm}[20]$.

Biomassa fresca e biomassa seca de plântulas: Foram utilizadas 12 plântulas normais coletadas no teste de emergência, as quais foram medidas em balança analítica para medição da biomassa fresca. Em seguida, as plântulas oriundas das repetições foram colocadas em sacos de papel e levadas para secar na estufa, a $65^{\circ} \mathrm{C}$ durante $72 \mathrm{~h}$, conforme [20] e posteriormente medida a biomassa seca com auxílio da balança analítica.

Os dados provenientes das avaliações foram submetidos ao teste de $\mathrm{F}$ associado à análise de variância e, quando significativos a 1 e 5\% de probabilidade, aplicou-se o teste de Tukey a fim de comparar as médias dos fatores em estudo, com o auxílio do programa SISVAR [21].

\section{RESULTADOS E DISCUSSÃO}

Os resultados da análise de variância das características estudadas para as fontes de variações híbridos de canola, profundidade de semeadura e substratos, e suas interações encontram-se expressos na Tabela 1. A interação entre híbridos de canola, em diferentes profundidades e substratos não apresentou diferença entre as variáveis avaliadas. Notou-se, que ocorreu interação significativa entre híbridos de canola $(\mathrm{H})$ e substratos $(\mathrm{S})$ para as características de comprimento de raiz (CR), comprimento de plântulas inteiras (CPI) e massa fresca de plântula (MFP)

Quando cultivados na areia o Híbrido Hyola 61 teve maior CR e CPI que o Híbrido Hyola 443. No entanto quando cultivados no solo 'Hyola 443' teve maior MFP que 'Hyola 61' (Tabela 2). Sempre que cultivados no solo ambos os híbridos tiveram melhores desempenhos em CR, CPI e MFP que quando cultivados na areia. Os valores maiores de CR foram medidos no substrato solo para ambos híbridos, com 5,23 e 5,40 cm, para Hyola 61 e Hyola 433, respectivamente. Um dos fatores que comanda a distribuição radicular no solo é o genótipo da cultivar/híbrido, porém ele pode sofrer influências de outros fatores referentes ao próprio substrato, como fertilidade, densidade, textura quantidade de oxigênio e água, temperatura e, também, pelas condições nas quais a espécie tende a se desenvolver, podendo citar a competição e espaçamento [22]. 
Tabela 1 - Valores de $F$ da análise de variância para as variáveis respostas quanto aos fatores profundidade $(P)$ de semeadura de híbridos $(H)$ de canola e substratos $(S)$, bem como a interação destes fatores, sob as variáveis índice de velocidade de emergência (IVE), emergência (E), plântulas não emergidas $(P N E)$, plântulas normais $(P N)$, plântulas anormais $(P A)$, comprimento de raiz $(C R)$, comprimento de plântulas inteiras (CPI), altura de plântulas (ALT), massa fresca de plântulas $(M F P) e$ massa seca de plântulas (MSP).

\begin{tabular}{llllllllllll}
\hline FV & GL & IVE & E & PNE & PN & PA & CR & CPI & ALT & MPF & MSP \\
\hline S & 1 & $3,91^{\text {ns }}$ & $3,29^{\text {ns }}$ & $3,29^{\text {ns }}$ & $81,61^{* *}$ & $81,63^{* *}$ & $54,62^{* *}$ & $246,48^{* *}$ & $196,74^{* *}$ & $174,07^{* *}$ & $15,99^{* *}$ \\
Erro1 & 7 & - & - & - & - & - & - & - & - & - & - \\
P & 2 & $35,16^{* *}$ & $0,08^{\text {ns }}$ & $2,66^{\text {ns }}$ & $0,91^{\text {ns }}$ & $0,99^{\text {ns }}$ & $12,89^{* *}$ & $0,31^{\text {ns }}$ & $27,82^{* *}$ & $11,58^{* *}$ & $19,49^{* *}$ \\
H & 1 & $0,4^{\text {ns }}$ & $22,81^{* *}$ & $22,81^{* *}$ & $59,04^{* *}$ & $59,04^{* *}$ & $10,53^{* *}$ & $9,58^{* *}$ & $0,18^{\text {ns }}$ & $12,07^{* *}$ & $12,83^{* *}$ \\
SxH & 1 & $0,33^{\text {ns }}$ & $0,02^{\text {ns }}$ & $0,02^{\text {ns }}$ & $0,06^{\text {ns }}$ & $0,06^{\text {ns }}$ & $23,69^{* *}$ & $23,38^{* *}$ & $0,28^{\text {ns }}$ & $6,67^{* *}$ & $0,05^{\text {ns }}$ \\
SxP & 2 & $3,06^{* *}$ & $0,02^{\text {ns }}$ & $0,02^{\text {ns }}$ & $0,07^{\text {ns }}$ & $0,07^{\text {ns }}$ & $2,26^{\text {ns }}$ & $3,61^{*}$ & $1,01^{\text {ns }}$ & $1,81^{\text {ns }}$ & $2,24^{\text {ns }}$ \\
SxHxP & 2 & $1,19^{\text {ns }}$ & $1,08^{\text {ns }}$ & $1,08^{\text {ns }}$ & $0,04^{\text {ns }}$ & $0,04^{\text {ns }}$ & $0,98^{\text {ns }}$ & $0,20^{\text {ns }}$ & $0,97^{\text {ns }}$ & $0,05^{\text {ns }}$ & $0,04^{\text {ns }}$ \\
SxHxP & 2 & $1,15^{\text {ns }}$ & $0,28^{\text {ns }}$ & $0,28^{\text {ns }}$ & $0,68^{\text {ns }}$ & $0.68^{\text {ns }}$ & $1,02^{\text {ns }}$ & $0,16^{\text {ns }}$ & $0,70^{\text {ns }}$ & $0,82^{\text {ns }}$ & $1,33^{\text {ns }}$ \\
Erro2 & 77 & - & - & - & - & - & - & - & - & - & - \\
\hline Total & 95 & - & - & - & - & - & - & - & - & - & - \\
\hline CV1 $(\%)$ & 10,60 & 5,93 & 40,76 & 7,17 & 17,73 & 11,65 & 6,50 & 9,24 & 19,60 & 25,38 \\
CV2 (\%) & 12,59 & 9,30 & 63,90 & 16,04 & 39,67 & 10,91 & 7,32 & 11,43 & 18,49 & 24,14 \\
\hline
\end{tabular}

FV: Fonte de variação; GL: Graus de liberdade; CV: Coeficiente de Variação; ${ }^{n s}$ : não significativo $* * e$

* significativo a 1 e $5 \%$ de probabilidade e pela análise de variância associada ao teste de F.

Tabela 2. Comprimento de raiz (CR), comprimento de plântula inteira (CPI) e massa fresca de plântulas (MFP) de dois híbridos de canola sob efeito de substratos (Subs).

\begin{tabular}{ccccccc}
\hline Subs & \multicolumn{2}{c}{ CR $(\mathbf{c m})$} & \multicolumn{2}{c}{ CPI $(\mathbf{c m})$} & \multicolumn{2}{c}{ MFP $(\mathbf{g})$} \\
\cline { 2 - 7 } & Hyola 61 & Hyola433 & Hyola 61 & Hyola433 & Hyola 61 & Hyola433 \\
\hline Areia & $4,90 \mathrm{aB}$ & $4,02 \mathrm{bB}$ & $7,50 \mathrm{aB}$ & $6,57 \mathrm{bB}$ & $0,092 \mathrm{aB}$ & $0,096 \mathrm{aB}$ \\
Solo & $5,23 \mathrm{aA}$ & $5,40 \mathrm{aA}$ & $8,57 \mathrm{aA}$ & $8,78 \mathrm{aA}$ & $0,147 \mathrm{bA}$ & $0,175 \mathrm{aA}$ \\
\hline
\end{tabular}

* Médias seguidas por mesma letra minúscula na linha e maiúscula na coluna não diferem entre si pelo teste de Tukey a $5 \%$ de probabilidade.

A interação estudada entre profundidade de semeadura e tipo de substrato foi significativa para comprimento de plântulas inteiras (CPI) e índice de velocidade de emergência (IVE). As plântulas de canola tiveram maior CPI quando cultivadas em solo, independentemente da profundidade de semeadura (Tabela 3). Porém quando semeado na areia na profundidade de $3 \mathrm{~cm}$, a canola teve maior CPI que quando semeada a $2 \mathrm{~cm}$ mas sem diferir da profundidade de $1 \mathrm{~cm}$. No entanto, quando semeada em solo não apresentou diferenças para CPI nas profundidades de semeadura estudadas.

Tabela 3. Comprimento de planta inteira (CPI) e índice de velocidade de emergência (IVE) em função de substratos (solo e areia) e profundidade (Prof) de semeadura de híbridos de canola.

\begin{tabular}{ccccc}
\hline & \multicolumn{2}{c}{ CPI $(\mathbf{c m})$} & \multicolumn{2}{c}{ IVE } \\
\cline { 2 - 5 } Prof & Areia & Solo & Areia & Solo \\
\cline { 2 - 5 } $\mathbf{1}$ & $7,10 \mathrm{bAB}$ & $8,64 \mathrm{aA}$ & $20,49 \mathrm{aA}$ & $19,81 \mathrm{aA}$ \\
$\mathbf{2}$ & $6,76 \mathrm{bB}$ & $8,83 \mathrm{aA}$ & $17,17 \mathrm{aB}$ & $18,05 \mathrm{aAB}$ \\
$\mathbf{3}$ & $7,25 \mathrm{bA}$ & $8,56 \mathrm{aA}$ & $14,43 \mathrm{bC}$ & $16,51 \mathrm{aB}$ \\
\hline
\end{tabular}

* Médias seguidas de mesma letra minúscula na linha e maiúscula na coluna não diferem entre si pelo teste de Tukey a $5 \%$ de probabilidade.

Com relação ao IVE constatou-se que teve diferença significativa entre os substratos apenas quando se semeou a canola na profundidade de semeadura $(3 \mathrm{~cm})$, pois o IVE foi maior quando semeada no solo que na semeadura em areia (Tabela 3). Independentemente do tipo de substrato a canola teve maior IVE quando semeada nas profundidades 1 e $2 \mathrm{~cm}$. Este fato ocorreu possivelmente porque em profundidades menores as plântulas enfrentam menor resistência física para emitir a parte aérea, além disso, leva menor tempo para emergirem do que em profundidades maiores, o que pode levar a um desenvolvimento mais rápido, e, consequentemente maior IVE 
$[11,23]$. No entanto, predispõem as sementes a variações ambientais como excesso ou déficit hídrico ou térmico, que podem originar a plântulas pequenas e frágeis [23].

A qualidade das sementes é um fator que está diretamente relacionado à altas taxas de germinação, vigor e sanidade, assim como, a garantia da pureza genética e física [24]. Os híbridos de canola se diferenciaram considerando as variáveis analisadas (Tabela 4). Para as variáveis emergência de plântulas (E), plantas normais (PN), comprimento de raiz (CR), comprimento de planta inteira (CPI), massa fresca de plântulas (MFP) e massa seca de plântulas (MSP) o híbrido o Hyola 433 mostrou-se superior ao Hyola 61. Levando em consideração que este necessita de maior disponibilidade hídrica [10], a irrigação presente na casa de vegetação pode ser um fator que influenciou, positivamente, a emergência de plântulas do híbrido Hyola 433.

Tabela 4. Emergência de plântulas (E), plântulas não emergidas (PNE), plântulas anormais (PA), plântulas normais $(P N)$, comprimento de raiz $(C R)$, comprimento de plântula inteira $(C P I)$, massa fresca de plântula (MFP) e massa seca de plântulas (MSP) de híbridos de canola em diferentes profundidades $e$ substratos.

\begin{tabular}{|c|c|c|c|c|c|c|c|c|}
\hline Hibrido & $\mathrm{E}(\%)$ & PNE (\%) & PA (\%) & PN (\%) & $\mathrm{CR}(\mathrm{cm})$ & CPI (cm) & MFP (g) & MSP (g) \\
\hline Hyola 61 & $83,33 \mathrm{~b}$ & $16,67 \mathrm{a}$ & $37,75 \mathrm{a}$ & $62,25 \mathrm{~b}$ & $4,71 \mathrm{~b}$ & $8,04 \mathrm{~b}$ & $0,119 \mathrm{~b}$ & $0,012 \mathrm{~b}$ \\
\hline Hyola433 & $91,25 \mathrm{a}$ & $8,75 \mathrm{~b}$ & $19,83 \mathrm{~b}$ & $80,17 \mathrm{a}$ & $5,06 \mathrm{a}$ & $7,68 \mathrm{a}$ & $0,136 \mathrm{a}$ & $0,015 \mathrm{a}$ \\
\hline
\end{tabular}

Em relação às plântulas não emergidas (PNE), o Hyola 61 mostrou-se mais prejudicado, ou seja, com maior PNE e com maior percentual de plântulas anormais (PA). Segundo Migliorini et al. (2017) [25] lotes e cultivares de sementes podem apresentar desempenhos diferentes em campo e laboratório, tornando-se necessária a realização de vários testes a fim de averiguar a qualidade das sementes.

O substrato solo proporcionou maior CR, CPI, ALT, MFP e MSP (Tabela 5). A disponibilidade de água é variável em função das características físicas dos substratos [26]. Esta pode ter influenciado a velocidade da embebição da semente e, por conseguinte, a formação de plântulas com maior vigor. Pois solos argilosos possuem melhor disponibilidade de água que areia, conseguindo absorver e armazenar água em maior quantidade. Além de disponibilizar nutrientes como o cálcio, que é o principal responsável pelo crescimento das raízes [27, 28].

Tabela 5. Plântulas anormais (PA), comprimento de raiz (CR), comprimento de plântula inteira (CPI), altura de plântula (ALT), massa fresca de plântula (MFP) e massa seca de plântulas (MSP) de híbridos canola em diferentes substratos (SUBS) e profundidades de semeadura.

\begin{tabular}{lrrrrrc}
\hline SUBS & PA $(\%)$ & CR $(\mathbf{c m})$ & CPI $(\mathbf{c m})$ & ALT $(\mathbf{c m})$ & MFP $(\mathbf{g})$ & MSP $(\mathbf{g})$ \\
\hline Areia & $33,50 \mathrm{a}$ & $4,46 \mathrm{~b}$ & $7,04 \mathrm{~b}$ & $2,56 \mathrm{~b}$ & $0,094 \mathrm{~b}$ & $0,012 \mathrm{~b}$ \\
Solo & $24,08 \mathrm{~b}$ & $5,32 \mathrm{a}$ & $8,68 \mathrm{a}$ & $3,34 \mathrm{a}$ & $0,161 \mathrm{a}$ & $0,015 \mathrm{a}$ \\
\hline * Médias seguidas de & mesma letra & na coluna não diferem entre si pelo teste de Tukey a $5 \%$ de \\
probabilidade.
\end{tabular}

O IVE, CR, MFP e MSP foi superior na profundidade de $1 \mathrm{~cm}$ (Tabela 6). A semeadura em profundidades pequenas é um fator esperado, pois, quanto menor a profundidade menor também a quantidade de solo a ser rompida pela semente [29]. Concordando com Cardoso et al. (2008) [30], os quais analisaram o índice de velocidade de emergência e verificaram que esse diminuiu de forma linear com as profundidades de semeadura.

$\mathrm{O}$ aumento em profundidade de semeadura influenciou negativamente a MFP (Tabela 6) e, consequentemente, a MSP, resultado que também foi observado por Koch et al. (2015) [11]. Estes autores explicam que, na semeadura em menores profundidades, no caso $1 \mathrm{~cm}$, as plântulas foram mais eficientes na exploração de reservas contidas nas sementes, o que resultou em maior acúmulo de matéria seca. 
Tabela 6. Índice de velocidade de emergência (IVE), comprimento de raiz (CR), altura de plântula (ALT), massa fresca de plântula (MFP) e massa seca de plântulas (MSP) de híbridos de canola sob efeito de profundidades de semeadura (PROF).

\begin{tabular}{cccccc}
\hline PROF & IVE & CR $(\mathbf{c m})$ & ALT $(\mathbf{c m})$ & MFP $(\mathbf{g})$ & MSP $(\mathbf{g})$ \\
\cline { 2 - 6 } $\mathbf{1}$ & $20,15 \mathrm{a}$ & $5,27 \mathrm{a}$ & $2,60 \mathrm{~b}$ & $0,143 \mathrm{a}$ & $0,016 \mathrm{a}$ \\
$\mathbf{2}$ & $17,61 \mathrm{~b}$ & $4,73 \mathrm{~b}$ & $3,06 \mathrm{a}$ & $0,124 \mathrm{~b}$ & $0,013 \mathrm{~b}$ \\
$\mathbf{3}$ & $15,47 \mathrm{c}$ & $4,65 \mathrm{~b}$ & $3,20 \mathrm{a}$ & $0,115 \mathrm{~b}$ & $0,011 \mathrm{~b}$ \\
\hline
\end{tabular}

* Médias seguidas de mesma letra na linha não diferem entre si pelo teste de Tukey a 5\% de probabilidade.

Esta redução conjunta de massa de plântulas, como consequência do crescimento dos diferentes órgãos (raiz e parte aérea), consiste em fator que prejudica as plântulas nos estádios de desenvolvimento inicial, conforme relatam Pedó et al. (2013) [12]. De acordo com estes autores, a diminuição do crescimento da parte aérea afeta a posição e bem como a distribuição de massa verde designada à formação de novas folhas o que afeta a formação do arranjo fotossintético da planta, e o reduzido crescimento do sistema radicular reflete em menor absorção de água e nutrientes. Este padrão de desempenho em função da profundidade de semeadura é frequentemente relatado para outras culturas como feijão [12] e soja [31], dentre outros, e para a própria canola [11].

Contudo, a recomendação de semeadura da canola é para ser realizada nas profundidades de 1 ou $2 \mathrm{~cm}$. A maioria dos relatos de trabalhos de campo realizam a semeadura a $2 \mathrm{~cm}$ por razões práticas que influenciam o rendimento dos híbridos, que podem estar associados ao solo, clima, semente, máquinas e operadores [32].

A profundidade de semeadura é típica de cada cultura e quando ideal, favorece a germinação e emergência uniforme de plântulas. Profundidades grandes podem dificultar a plântula a emergir, porém em pequenas profundidades as plantas ficam muito suscetíveis a modificações climáticas, como excesso de chuvas ou secas e grandes mudanças de temperatura [33].

A relação altura de plântula (ALT) foi variável também e nas profundidades de 2 e $3 \mathrm{~cm}$ se mostrou mais bem desenvolvida do que na profundidade de $1 \mathrm{~cm}$. Já a Massa fresca de plântulas (MSF) e Massa seca de plântulas (MSP) foram superiores na profundidade de $1 \mathrm{~cm}$ levando em consideração que elas emergiram primeiro, tendo-se em vista que se desenvolveram melhor.

\section{CONCLUSÃO}

O híbrido de canola Hyola 433 apresentou melhor desempenho de plântulas, independentemente do tipo de substrato.

A profundidade ideal para semeadura de canola foi a $1 \mathrm{~cm}$, tendo em vista o melhor desenvolvimento de plântulas.

Avaliações do desempenho de plântulas de canola realizadas em solo possibilitam maior proximidade às condições encontras em campo, portanto, indica-se avaliação de sementes neste substrato, e não somente em leito de areia.

\section{REFERÊNCIAS BIBLIOGRÁFICAS}

1. Ávila MR, Braccini AL, Scapim CA, Martorelli DT, Albrecht LP. Testes de laboratório em sementes de canola e a correlação com a emergência das plântulas em campo. Rev Bras Sementes. 2005;27(1):6270, doi: 10.1590/S0101-31222005000100008.

2. Junior Seabra E, Pozzo DMD, Santos RF. Estudo sobre a cultura de canola (Brassica napus L.) no contexto de culturas energéticas. In: II Seminário de engenharia de energia na agricultura. Acta Iguazu. 2017;6(5):140-146.

3. CONAB - Companhia Nacional de Abastecimento. Acompanhamento da safra brasileira de grãos. Observatório Agrícola. Safra2019/2020, quarto levantamento, 2020;4:1-25.

4. Chavarria G, Tomm GO, Muller A, Mendoça HF, Mello N, Betto MS. Índice de área foliar em canola cultivada sob variações de espaçamento e de densidade de semeadura. Cienc Rural. 2011 Dez;41(12):2084-2089, doi: 10.1590/S0103-84782011001200008.

5. Mori C, Tomm GO, Ferreira PEP. Aspectos econômicos e conjunturais da cultura da canola no mundo e no Brasil. Documentos online 149. 2014. Passo Fundo: Embrapa Trigo; p.36. Disponível em: http://www.cnpt.embrapa.br/biblio/do/p_do149.htm. Acesso em 09 jan. 2020. 
6. Silva LFL, Gonçalves WM, Maluf WR, Resende LV, Licursi V, Moretto P. Balanço energético da cultura de canola, acompanhamento da produção de biodiesel. Cienc Rural. 2017 Dez;47(2):1-5, doi: 10.1590/0103-8478cr20151084.

7. Ferreira PEP, Tomm GO, Antunes JM, Marsaro Júnior Al. Dinâmica de capacitação técnica e de transferência de tecnologia para o sistema produtivo de canola. In: Simpósio brasileiro de canola, 1, 2017, Passo Fundo. Anais... Brasília, DF: Embrapa, 2017. p. 82-87.

8. Bandeira TP, Chavarria G, Tomm GO. Desempenho agronômico de canola em diferentes espaçamentos entre linhas e densidades de plantas. Pesq agropec bras. 2013. Out;48 (10):1332-1341, doi: 10.1590/S0100-204X2013001000004.

9. Silva JAG, Motta MB, Winch JA, CrestanI M, Fernandes SBV, Berto JL, Gaviraghi F, Martins JAK, Wagner JF, Valentini APF, Zambonato F. Dessecação em pré-colheita como estratégia de manejo na redução de perdas por fatores de ambiente em canola. R Bras Agrociência. 2011 Jan;17(1-4):15-24.

10. Tomm GO, Wietholer S, Dalmago CA, Santos HP. Tecnologia para a produção de canola no Rio Grande do Sul. Passo Fundo; Embrapa Trigo, 2009. 41p.

11. Koch F, Gehling VM, Pedó T, Tunes LVM, Villela FA, Aumonde TZ. Expressão do vigor de sementes e desempenho inicial de plantas de canola: efeito da profundidade de semeadura. Rev Agric. 2015;90(2):193-201.

12. Pedó T, Martinazzo EG, Aumonde TZ, Villela FA. In: Sementes: Produção qualidade e inovações tecnológicas. Schuch LOB, Vieira JFV, Rufino CA, Júnior JSA, editores. Princípios fisiológicos na produção de sementes. Pelotas Editora e Gráfica Universitária, 2013. 571 p.

13. Tomm GO. Canola: alternativa de renda e benefícios para os cultivos seguintes. Rev Plantio Direto. 2006;15(94):4-8.

14. Pizolotto CA, Boller W, Lângaro NC, Tomm GO. Rendimento de grãos e perdas na colheita de canola em resposta a diferentes manejos de colheita mecanizada. Vivências: Revista Eletrônica de Extensão da URI. 2017 Mai;13(24):411-417.

15. BRASIL Ministério da Agricultura Pecuária e Abastecimento. Regras para análise de sementes. ed. 1 Brasília: Mapa/ACS, 2009. 161 p.

16. Amaro HTR, David AMSS, Assis MO, Rodrigues BRA, Cangussú LVS, Oliveira MB. Testes de vigor para avaliação da qualidade fisiológica de sementes de feijoeiro. Rev Ci Agr. 2015 Set;38(3):383-389.

17. Silva RF, Bressan RT, Santos RF, Lenz NBG, Zilli BN. Influência da profundidade de semeadura da canola em seu estádio inicial. In: I seminário de engenharia de energia na agricultura. Acta Iguazu. 2016;5:127-134.

18. Alvares CA, Stape JL, Sentelhas PC, Gonçalves JLM, Sparovek G. Köppen's climate classification map for Brazil. Meteorol Zeitschrift. 2013;22(6):711-728.

19. Maguire JD. Speed of germination-aid in selection and evaluation for seedling emergence and vigor. Crop Sci. 1962;2(2):176-177, doi: 10.2135/cropsci1962.0011183X000200020033x.

20. Nakagawa J. Testes de vigor baseados no desempenho das plântulas. In: Krzyzanoski FC, Vieira RD, França Neto JB, editores. Vigor de sementes: conceitos e testes. 1999 2.1-2.24; Londrina, PR. Embrapa Soja: ABRATES.

21. Ferreira DF. Sisvar: a computer statistical analysis system. Ciênc agrotec. 2011 Nov;35(6):1039-1042, doi: 10.1590/S1413-70542011000600001.

22. Gonçalves JLM, Mello SLM. O sistema radicular das árvores. In: Nutrição e fertilização de florestas. Piracicaba: IPEF, cap. 8, 2000. p. 221-267.

23. Alves AU, Cardoso EA, Alixandre TF, Cavalcante IHL, Calvante-Bechmann MZ. Emergência de plântulas de fava em função de posições e profundidade de semeadura. Biosci J. 2015 Jan;30(1):33-42.

24. Carvalho NM, Nakagawa J. 2012 Sementes: ciência, tecnologia e produção. Jaboticabal:Funep, 2012. $590 \mathrm{p}$.

25. Migliorini P, Lazarotto M, Muller J, Oruoski P, Bovolini MP, Barbieri M, Tunes LVM, Muniz MFB. Qualidade fisiológica, sanitária e transmissão de patógenos em sementes de canola. Colloquium Agrariae. 2017 Set;13(03):67-76, doi: 10.5747/ca.2017.v13.n3.a175.

26. Figliolia MB, Oliveira EC, Pinã-Rodrigues FCM Análise de sementes. In: Aguiar IB, Pinã-Rodrigues FCM, Figliolia MB. Sementes florestais tropicais. Brasília: ABRATES, 1993, p. 137-174.

27. Mendonça-Angelotti J, Roboldi LB, Soares CDF, Castro PRC, Kluge RA. Canola (Brassica napus L. 2016. Série Produtor Rural 61. Piracicaba:ESALQ; 32 p.

28. Prado RM, Natale W. Calagem na nutrição de cálcio e no desenvolvimento do sistema radicular da goiabeira. Pesq. Agropec. Bras. 2004 Out; 39(10):1007-1012, doi: 10.1590/S0100$204 X 2004001000008$.

29. Civiero JC, Marchese JA, Biezus E, Matei G, Benin G, Cassol LC, Paladini MV, Capelin D. Tamanho de semente e profundidade de semeadura em relação à tolerância a deficiência hídrica em trigo. In: XIV SICITE - UTFPR, 2015; 1:1-4. 
30. Cardoso EA, Alves EU, Bruno RLA, Alves AU, Alves AU, Silva KB. Emergência de plântulas de Erythrina velutina em diferentes posições e profundidades de semeadura. Ciênc Rural. 2008; 38(9):2618-2621.

31. Aikins SHM, Afuakwa JJ, Nkansah EO. Effect of different sowing depths on soybean growth and dry matter yield. Agric Biol J North Am. 2011; 2(9):1273-1278, doi: 10.5251 / abjna.2011.2.9.1273.1278.

32. Balastreire, LA. Máquinas agrícolas. Embrapa, São Paulo: Manole, 1987. 307p.

33. Tillmann MAA, Piana Z, Cavariani C, Minami K. Efeito da profundidade de semeadura na emergência de plântulas de tomate (Lycopersicon esculentum Mill.). Sci agric. 1994;51(2):260-263, doi: 10.1590/S0103-90161994000200010. 